\title{
Research Paper: Status of the Acute Respiratory Symptoms, Pulmonary Function Test, and Chest Radiograph Among Professional Firefighters of the Plasco Trade Center Disaster in Active Firefighting of Tehran, Iran in 2016
}

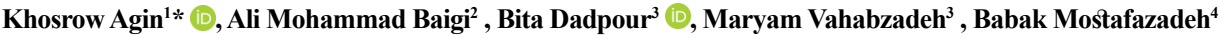 \\ 1. Pulmonologist \& Pulmonary Critical Care, Logman Hakeem General Teaching Hospital, Shahid Beheshti University of Medical Sciences, Tehran, Iran. \\ 2. Clinical Psychology, Faculty Of Medicine, Shahid Beheshti University of Medical Sciences, Tehran, Iran. \\ 3. Medical Toxicology Research Center, Mashhad University of Medical Sciences, Mashhad, Iran. \\ 4. Toxicological Research Center, Shahid Beheshti University of Medical Sciences, Tehran, Iran.
}

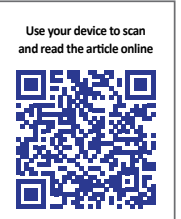

Citration: Agin Kh, Mohammad Baigi A, Dadpour B, Vahabzadeh M, Mostafazadeh B. Status of the Acute Respiratory Symptoms, Pulmonary Function Test, and Chest Radiograph Among Professional Firefighters of the Plasco Trade Center Disaster in Active Firefighting of Tehran, Iran in 2016. International Journal of Medical Toxicology and Forensic Medicine. 2019; 9(4):199-204. https:// doi.org/10.32598/ijmtfm.v9i4.25105

doi ${ }^{\circ}$ https://doi.org/10.32598/ijmtfm.v9i4.25105

\section{(c) (1) (\$)}

Article info:

Received: 27 Apr 2019

First Revision: 10 May 2019

Accepted: $20 \mathrm{Jul} 2019$

Published: 01 Oct 2019

Keywords:

Firefighter, Respiratory symptoms, Pulmonary function test, Chest radiography

\section{ABSTRACT}

Background: Firefighting is a high-risk occupation. The firefighters can be involved in acute and chronic diseases. The study was conducted to investigate the acute symptoms of pulmonary problems, chest radiography, and pulmonary function testing among the professional firefighters of Tehran Firefighting Stations in active firefighting of the Plasco trade center disaster.

Methods: A call was announced by the national Fars news agency to examine the firefighters in the Plasco trade center disaster.

Results: A total of 56 firefighters completed the study design. They were male, commonly at a young age, and less than their 3rd decade. Upper respiratory tract symptoms were at a higher frequency than a lower airway tract; $98 \%$ of the subjects complained of respiratory symptoms. Chest abnormality was $24 \%$ and normal acute short-term spirometry was $87 \%$. Acute occupational bronchitis was a prominent respiratory disease.

Conclusion: Acute toxic inhalation respiratory diseases, including acute bronchitis, asthmalike disease, and laryngitis were found in our study. Medical monitoring is necessary for the detection of adverse health effects in the exposure, post-exposure, and long lifetime.

\section{* Corresponding Author:}

Khosrow Agin, MD.

Address: Pulmonologist \& Pulmonary Critical Care, Logman Hakeem General Teaching Hospital, Shahid Beheshti University of Medical Sciences, Tehran, Iran.

Tel: +98 (912) 1170019

E-mail: khosrow.agin@yahoo.com 


\section{Introduction}

A

firefighting is one of the high-risk occupations. The death rate of injury was 16.6 per 100,000, which is 4 times more than 100,000 overall occupations [1]. They are exposed to premature or late-life complications [2]. Various illnesses related to firefighting, such as trauma [2], skeletal injury, toxicity, psychological [3], suicide [4], cancer [5], stroke [6], and heart attack [7] diseases can be found in database searching.

Like another organ, the respiratory system of the firefighters is also affected by occupational injuries. Current studies have shown that the adverse effects of this occupation can be affected by the respiratory system as obstructive airway diseases [8], airway irritability [9], lung cancer [10], and impairment of the pulmonary function [11]. The varieties of the firefighting exposed- diseases depend on the use of an individual protection device, the length of time and frequency of the rescue missions, the environmental contamination, and medical-monitoring follow-up. Diseases of the respiratory system appear in two distinct clinical features, acute [12] or chronic [13], during the lifetime of the firefighters.

The current study was conducted to investigate the acute symptoms of pulmonary problems, chest radiography, and pulmonary function testing among the professional firefighters of Tehran Firefighting Stations in active firefighting of the Plasco trade center disaster.

\section{Materials and Methods}

The present research is a cross-sectional study. It was conducted in the Shahid Beheshti University of Medical Science, Loghman Hakim general teaching Hospital, Tehran, Iran in 2017.
The study was conducted through a call to Fars News Agency. All of the firefighters' teams were invited to collaborate after being allowed by the head of the fire department in Tehran. The study was conducted at the time of the accident in Loghman Hakim Hospital. The hospital was one of the medical centers near the site of the accident.

The Plasco trade center building was one of the oldest shopping centers in Tehran. It had a long history of clothing production. A fire incident occurred in 2016.

All the firefighters that would like to be evaluated for the health system were enrolled in the study. Their unwillingness or severity of pulmonary disease would have limited the research.

All subjects were examined after attending the health center. Both individuals and physicians completed a self-report and the medical questionnaire. It consisted of demographic data, history of smoking, the duration of employment in the service of firefighting, the common symptoms of the respiratory system diseases, and medical history. They were sent to perform pulmonary function testing and chest radiographs. Each subject was treated based on the seriousness of the symptoms.

The data were analyzed by software SPSS version 22 . Normality was assessed by the Kolmogorov-Smirnov test (Page $=0.001)$. The frequency of variation was reported as a percentage. Excel was used for displaying the results.

\section{Results}

The study was completed with 56 volunteer firefighters. They were all men. The Mean $\pm \mathrm{SD}$ age was $32.8 \pm 6.4$ years. It ranged from 21 to 47 years (Median=32 and
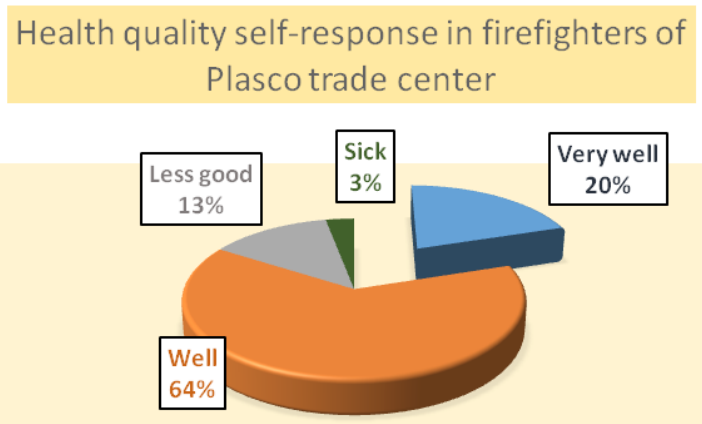

Figure 1. The frequency of health quality among firefighters in Plasco trade center disaster 


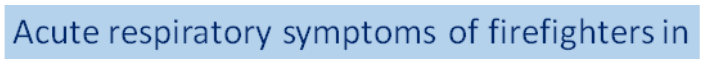

Plasco trade center

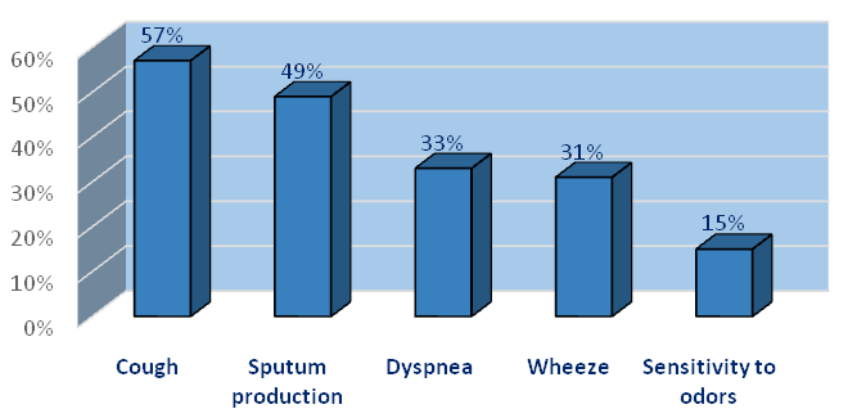

International Journal of
Medical Toxicology \& Forensic Medicine

Figure 2. The frequency distribution of acute lower respiratory tract symptoms among firefighters of Plasco trade center disaster

Mode=32). The Mean \pm SD of work time at the workplace of the Plasco trade center was $53.4 \pm 41$ hours. The range was 8 to 200 hours (Median=48 and Mode $=24$ ).

The self-personal assessment of their health quality status was as follows: figure 1 shows the frequency of health quality among firefighters in the Plasco trade center. Notable diseases, including hypertension, kidney disease, rheumatic diseases, and trauma were present in $9 \%$ of the population and $91 \%$ of them were healthy.

Generally, $7 \%$ used respiratory protective mask against fire smoke inhalation continuously and $73 \%$ used it partially; $20 \%$ did not use it. Figure 2 shows the frequency distribution of acute lower respiratory tract symptoms among firefighters of the Plasco trade center; $98 \%$ of complaints were related to acute respiratory symptoms. Figure 3 shows the acute symptoms of occupational exposure in the upper respiratory tract; $32 \%$ of the subjects revealed an abnormal finding on physical examination.
Over $93 \%$ of global rescue firefighters complained of up to 5 different respiratory symptoms. Figure 4 indicates the frequency of the number of symptoms in firefighters. Chest radiography detected the toxic inhalation exposure features caused by the fire environment in $24 \%$ of the cases. The distribution of chest radiography abnormality manifestations was presented more commonly in the middle-aged class of 40 to 49 years with a frequency of $40 \%$. The pulmonary function test was disclosed during active firefighting. The frequency of short-term spirometry in active firefighting was $4 \%$ obstructive and $87 \%$ normal patterns.

The frequency of physician diagnosis of toxic inducedinhalation diseases consisted of $55 \%$ as occupational acute bronchitis, $26 \%$ as asthma-like disease, and 19\% as normal. Frequency of fire smoke-induced laryngitis was associated with other inhalation diseases $13 \%$.
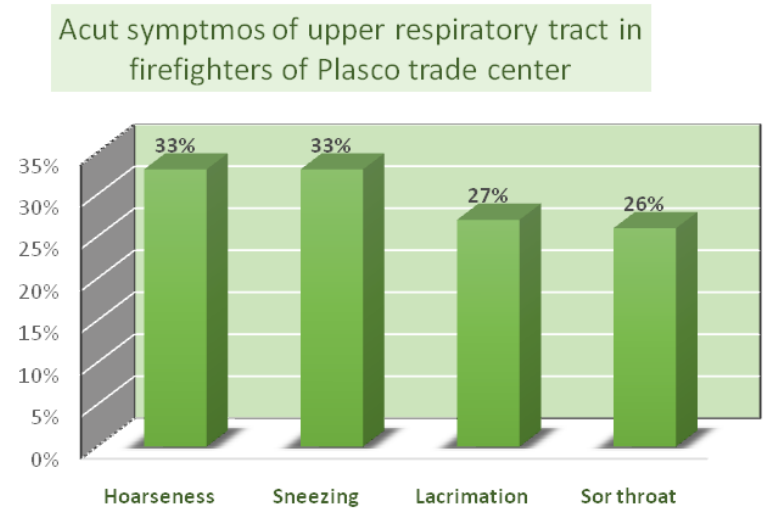

International Journal of
Medical Toxicology \& Forensic Medicine

Figure 3. The acute symptoms of occupational exposure in the upper respiratory tract among firefighters of Plasco trade center disaster 


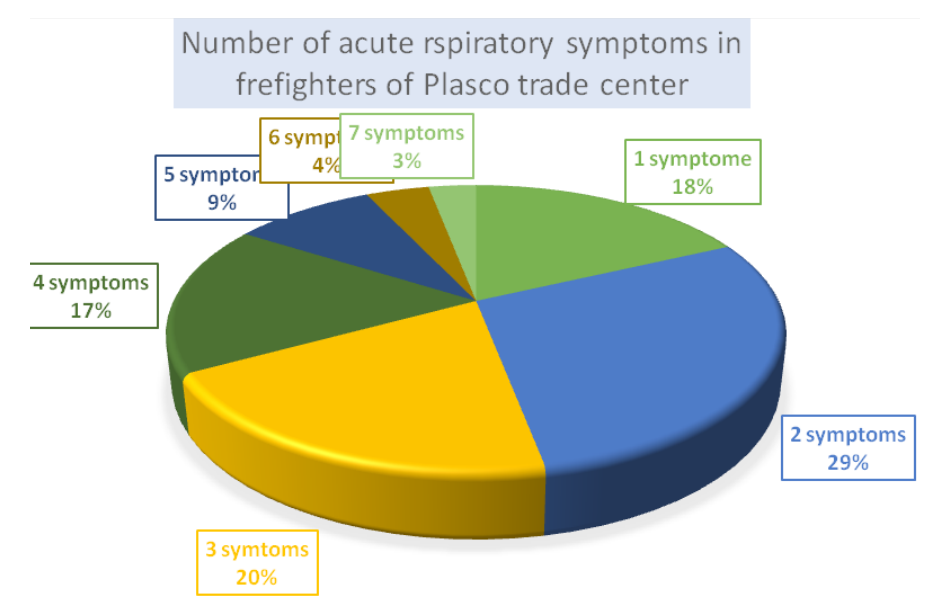

Figure 4. The frequency of number symptoms in firefighters of Plasco trade center disaster

\section{Discussion}

The prevalence of respiratory problems was $30 \%$ to $50 \%$ in different studies [14]. Acute symptoms of the respiratory system were remarkable among rescue professional firefighters of our study. They considered health in $84 \%$ of their cases. The most respiratory symptoms were related to the lower than the upper respiratory tracts. The lower respiratory tract exposed-symptoms were cough, sputum, and dyspnea, respectively. Its causes may be as follows: firefighters usually do not continuously use respiratory protection devices. A component of the neglect of respiratory protection may be related to hard-working conditions; however, it should be attempted in continuous education.

The combustion environment is similar to many chemical pollutants such as acid gases, aldehyde, and irritant particle matters. Fire smokes can cause both acute respiratory symptoms and chronic respiratory illnesses [12]. One of the motivations was working after a work time. They remained in the workplace after the end of the work time. This was their unofficial expression in the interview and disclosed by the data during the accident. Most fire extinguishers had many missions in the work experience. The use of personal protective equipment was not well done by the rescue team of firefighting of the Plasco trade center disaster based on the data. The marked frequency of numbers symptoms also confirmed the current outcome.

Sensitivity to odors is a reflection of bronchial hypersensitivity of the respiratory tract and most of them had an association with airway obstruction features such as wheezes. The presence of lung irritation was very significant in the results of our study. A high level of respiratory exposure to the heat and fire smoke was indi- cated in the workplace. The Plasco trade center was a clothing production center in Tehran. The burned clothes can be derived from high combustion, different chemical substances, and irritant gases. In addition, the collapsed building can produce a large volume of dust and devastating materials [15].

Bronchial hyperresponsiveness, dyspnea, cough, and wheeze are the common clinical manifestations of asthma [16] or asthma-like diseases/small airway disease onset after firefighting [17]. It was supported by pulmonary function test impairment as a pure obstructive and or mixed obstructive-restrictive pattern. Abnormality in spirometry parameters (forced vital capacity, forced expiratory volume in one second) was reported between $12 \%$ and $32 \%[18,19]$. Our result of spirometry was an improvement with current reports.

Sputum production and cough symptoms were significant in our self-report health and medical questionnaire. They were compatible with acute occupational bronchitis disease. It was also diagnosed by a physician. Postexposure of short-term spirometric changes parameters are not aided in the diagnosis and a normal finding. A chest x-ray may be normal or show congestion and peribronchial thickening. It was found with considerable frequency in our chest imaging. Airway obstructive diseases and bronchitis were reported in a few studies [20,21].

Respiratory system involvement may be supposed as a pyramidal model in toxic inhalation injuries. The upper respiratory tract is the first line exposed area. Hoarseness, cough, and sore throat are the cardinal clinical features of the upper respiratory tract disease as inducedfire smoke laryngitis. Our findings in the study may be suggested the current diseases. 
Burning eyes (3\%) and running nose (2\%) were reported in the recent study [22]. Our outcome revealed higher than the recent report and it may be because of the high concentration of environmental smoke-related symptoms and does not use protective equipment.

\section{Conclusion}

Acute toxic inhalation respiratory diseases, including acute bronchitis, asthma-like disease, and laryngitis were found in our study. Medical monitoring is necessary for the detection of adverse health effects in the exposure, post-exposure, and long lifetime.

\section{Ethical Considerations}

\section{Compliance with ethical guidelines}

All ethical principles were considered in this article. The participants were informed about the purpose of the research and its implementation stages; they were also assured about the confidentiality of their information; Moreover, They were allowed to leave the study whenever they wish, and if desired, the results of the research would be available to them.

\section{Funding}

This research did not receive any specific grant from funding agencies in the public, commercial, or not-forprofit sectors.

\section{Author's contributions}

Performing all the research phases of the current study, including conception; Design, data acquisition, interpretation and analysis of data, drafting the article, and final approval: Khosrow Agin; Announcing, gathering of the firefighters, and collecting information on questionnaires: Ali Mohammad Baigi and Babak Mostafazadeh.

\section{Conflict of interest}

The author declared no conflict of interest.

\section{Acknowledgements}

The author would like to appreciate the firefighters of the Plasco trade center, imaging ( Maryam Zinali), pulmonary function test (Mahnaze Soltanpour), manager (Nader Haghi MD.), and headquarter (Omidvar Rezai MD.) of Logman Hakim general teaching Hospital.

\section{References}

[1] Hsiao H, Whitestone J, Kau TY, Whisler R, Routley JG, Wilbur M. Sizing firefighters: Method and implications. Human Factors. 2014; 56(5):873-910. [DOI:10.1177/0018720813516359] [PMID] [PMCID]

[2] Ibrayeva A, Turdalieva B, Aimbetova G, Pleva L. General health status among firefighters and rescue operations workers. Georgian Medical News. 2017; (270):130-5.

[3] Yoo S, Komura K, Matsui Y, Maruyama S. [The stress symptoms and posttraumatic growth of dispatched firefighters following the great East Japan earthquake (Japanese)]. The Japanese Journal of Psychology. 2017; 87(6):644-50. [DOI:10.4992/ jjpsy.87.15309] [PMID]

[4] Stanley IH, Hom MA, Gai AR, Joiner TE. Wildland firefighters and suicide risk: Examining the role of social disconnectedness. Psychiatry Research. 2018; 266:269-74. [DOI:10.1016/j. psychres.2018.03.017] [PMID]

[5] Tsai RJ, Luckhaupt SE, Schumacher P, Cress RD, Deapen DM, Calvert GM. Risk of cancer among firefighters in California, 1988-2007. American Journal of Industrial Medicine. 2015 58(7):715-29. [DOI:10.1002/ajim.22466] [PMID] [PMCID]

[6] Gendron P, Lajoie C, Laurencelle L, Trudeau F. Cardiovascular disease risk factors in Québec male firefighters. Journal of Occupational and Environmental Medicine. 2018; 60(6):e3006. [DOI:10.1097/JOM.0000000000001309] [PMID]

[7] Su Y, Yang J, Song G, Li R, Xiang C, Li J. Development of a numerical model to predict the physiological strain of firefighter in a fire hazard. Scientific Reports. 2018; 8(3628):1-8. [DOI:10.1038/s41598-018-22072-8] [PMID] [PMCID]

[8] Witt M, Goniewicz M, Pawłowski W, Goniewicz K, Biczysko $\mathrm{W}$. Analysis of the impact of harmful factors in the workplace on the functioning of the respiratory system of firefighters. Annals of Agricultural and Environmental Medicine. 2017 24(3):406-10. [DOI:10.5604/12321966.1233561] [PMID]

[9] Aldrich TK, Weakley J, Dhar S, Hall CB, Crosse T, Banauch GI, et al. Bronchial reactivity and lung function after World Trade Center exposure. Chest. 2016; 150(6):1333-40. [DOI:10.1016/j.chest.2016.07.005] [PMID] [PMCID]

[10] Bigert C, Gustavsson P, Straif K, Taeger D, Pesch B, Kendzia B, et al. Lung cancer among firefighters: Smoking-adjusted risk estimates in a pooled analysis of case-control studies. Journal of Occupational and Environmental Medicine. 2016; 58(11):1137-43. [DOI:10.1097/JOM.0000000000000878] [PMID]

[11] Choi JH, Shin JH, Lee MY, Chung IS. Pulmonary function decline in firefighters and non-firefighters in South Korea. Annals of Occupational and Environmental Medicine. 2014; 26(1):9. [DOI:10.1186/2052-4374-26-9] [PMID] [PMCID]

[12] Greven FE, Rooyackers JM, Kerstjens HA, Heederik DJ Respiratory symptoms in firefighters. American Journal of Industrial Medicine. 2011; 54(5):350-5. [DOI:10.1002/ ajim.20929] [PMID]

[13] Webber MP, Glaser MS, Weakley J, Soo J, Ye F, Zeig-Owens R, et al. Physician-diagnosed respiratory conditions and mental health symptoms 7-9 years following the World Trade Center disaster. American Journal of Industrial Medicine. 2011; 54(9):661-71. [DOI:10.1002/ajim.20993] [PMID] [PMCID] 
[14] Gaughan DM, Cox-Ganser JM, Enright PL, Castellan RM, Wagner GR, Hobbs GR, et al. Acute upper and lower respiratory effects in wildland firefighters. Journal of Occupational and Environmental Medicine. 2008; 50(9):1019-28. [DOI:10.1097/JOM.0b013e3181754161] [PMID]

[15] Weakley J, Webber MP, Gustave J, Kelly K, Cohen HW, Hall CB, et al. Trends in respiratory diagnoses and symptoms of firefighters exposed to the World Trade Center disaster: 2005-2010. Preventive Medicine. 2011; 53(6):364-9. [DOI:10.1016/j.ypmed.2011.09.001] [PMID]

[16] Ribeiro M, de Paula Santos U, Bussacos MA, Terra-Filho $\mathrm{M}$. Prevalence and risk of asthma symptoms among firefighters in São Paulo, Brazil: A population-based study. American Journal of Industrial Medicine. 2009; 52(3):261-9. [DOI:10.1002/ajim.20669] [PMID]

[17] Prezant DJ, Weiden M, Banauch GI, McGuinness G, Rom WN, Aldrich TK, et al. Cough and bronchial responsiveness in firefighters at the World Trade Center site. New England Journal of Medicine. 2002; 347(11):806-15. [DOI:10.1056/NEJMoa021300] [PMID]

[18] Schermer T, Malbon W, Newbury W, Holton C, Smith M, Morgan M, et al. Spirometry and Impulse Oscillometry (IOS) for detection of respiratory abnormalities in metropolitan firefighters. Respirology. 2010; 15(6):975-85. [DOI:10.1111/j.14401843.2010.01809.x] [PMID]

[19] Rom WN, Reibman J, Rogers L, Weiden MD, Oppenheimer B, Berger K, et al. Emerging exposures and respiratory health: World Trade Center dust. Proceedings of the American Thoracic Society. 2010; 7(2):142-5. [DOI:10.1513/ pats.200908-092RM] [PMID] [PMCID]

[20] Feldman DM, Baron SL, Bernard BP, Lushniak BD, Banauch $\mathrm{G}$, Arcentales N, et al. Symptoms, respirator use, and pulmonary function changes among New York City firefighters responding to the World Trade Center disaster. Chest. 2004; 125(4):1256-64. [DOI:10.1378/chest.125.4.1256] [PMID]

[21] Weakley J, Webber MP, Ye F, Zeig-Owens R, Cohen HW, Hall CB, et al. Agreement between obstructive airways disease diagnoses from self-report questionnaires and medical records. Preventive Medicine. 2013; 57(1):38-42. [DOI:10.1016/j. ypmed.2013.04.001] [PMID]

[22] Miedinger D, Chhajed P, Stolz D, Gysin C, Wanzenried $\mathrm{A}$, Schindler $\mathrm{C}$, et al. Respiratory symptoms, atopy, and bronchial hyperreactivity in professional firefighters. European Respiratory Journal. 2007; 30(3):538-44 [DOI:10.1183/09031936.00015307] [PMID] 